\title{
Connecting in Online Technical Communication Courses: Addressing Usability Challenge for Students and Faculty Members
}

\author{
Marjorie Rush Hovde \\ Indiana University-Purdue University Indianapolis \\ mhovde@iupui.edu
}

\begin{abstract}
In designing and offering online technical communication courses, faculty members face many challenges, including attempting to assure the usability of the interface for students. This article addresses five of these challenges and provides options for faculty members to begin to address these challenges.
\end{abstract}

Index Terms - Effective online courses, heuristic analysis, usability in online courses, usability testing

\section{INTRODUCTION}

An electronic interface for online course delivery and interaction requires high levels of usability, both for students and for faculty members. In attempting to offer usable interfaces for online technical communication courses, faculty members face multiple challenges, but several options exist to address those challenges.

Usability plays an important role in online technical communication courses because of the applied nature of these courses and because usability serves as an important principle in technical communication. Interfaces for online technical communication courses should provide strong examples of usability, and technical communication faculty members should lead in creating interfaces of online learning management systems (LMS) to be as usable as possible. In an online course, students at least need to "access and retrieve relevant course materials, navigate to locate and interact with course elements, participate in group activities, complete assignments and, finally, construct meaning to achieve learning outcomes," [1, p. 35] activities that all require a usable interface.

Many familiar principles of usability for online course interfaces relate to non-academic situations. An educational context may have additional dimensions of usability, beyond those found in web sites designed for other purposes.

In addition to assuring that the student-facing part of an LMS is usable, it is also important to think about usability for instructors who develop course material, interact with students, and react to their work. If the instructor-facing interface is difficult to use, it can lead to frustration for faculty members already addressing multiple challenges in teaching online.

In this article, I address five challenges that faculty members face in attempting to provide usable interfaces in online technical communication courses. I finish by exploring options for addressing those challenges.

\section{Five ChALLENGES To USABILITY WITHIN AN LMS}

Technical communication (and other) faculty members may find one or more of the following five challenges when they teach courses online.

\section{LMS designers may not create optimally usable interfaces}

Technical communication faculty members may use a LMS designed by someone else [2] leading to interfaces that may not provide good usability. In the LMS interface illustrated in Figure 1, (Indiana University's Oncourse) students have to click on multiple links to complete assignments. For instance, to participate in a Discussion Forum, they have to go to the Assignments page seen in Figure 1, read the instructions, and then click on the Forum link in order to make their contributions. Although the structure may seem simple to experienced LMS users, inexperienced students sometimes have trouble navigating within this structure, especially when attempting to leave the Forum and return to the Assignments list.

In this same LMS, instructors face inconsistent design and inefficient means of revising course materials. For instance, Oncourse offers at least two ways to remove an item from a list. To remove an item from the Gradebook, an instructor opens an item and clicks on a link titled Remove. A message pops up to verify this action. To remove many items, instructors remove each one separately, an inefficient use of their time. On the other hand, to remove a file from Resources or Assignments, the instructor checks a box next to the item (or multiple items, as appropriate) and then selects Remove, as seen in Figure 2. All checked items are then removed, a much more efficient use of the instructor's time.

This is the author's manuscript of the article published in final edited form as:

Hovde, M. R. (2015). Connecting in online technical communication courses: Addressing usability challenge for students and faculty members. In 2015 IEEE International Professional Communication Conference (IPCC) (pp. 1-6). http://doi.org/10.1109/IPCC.2015.7235846 


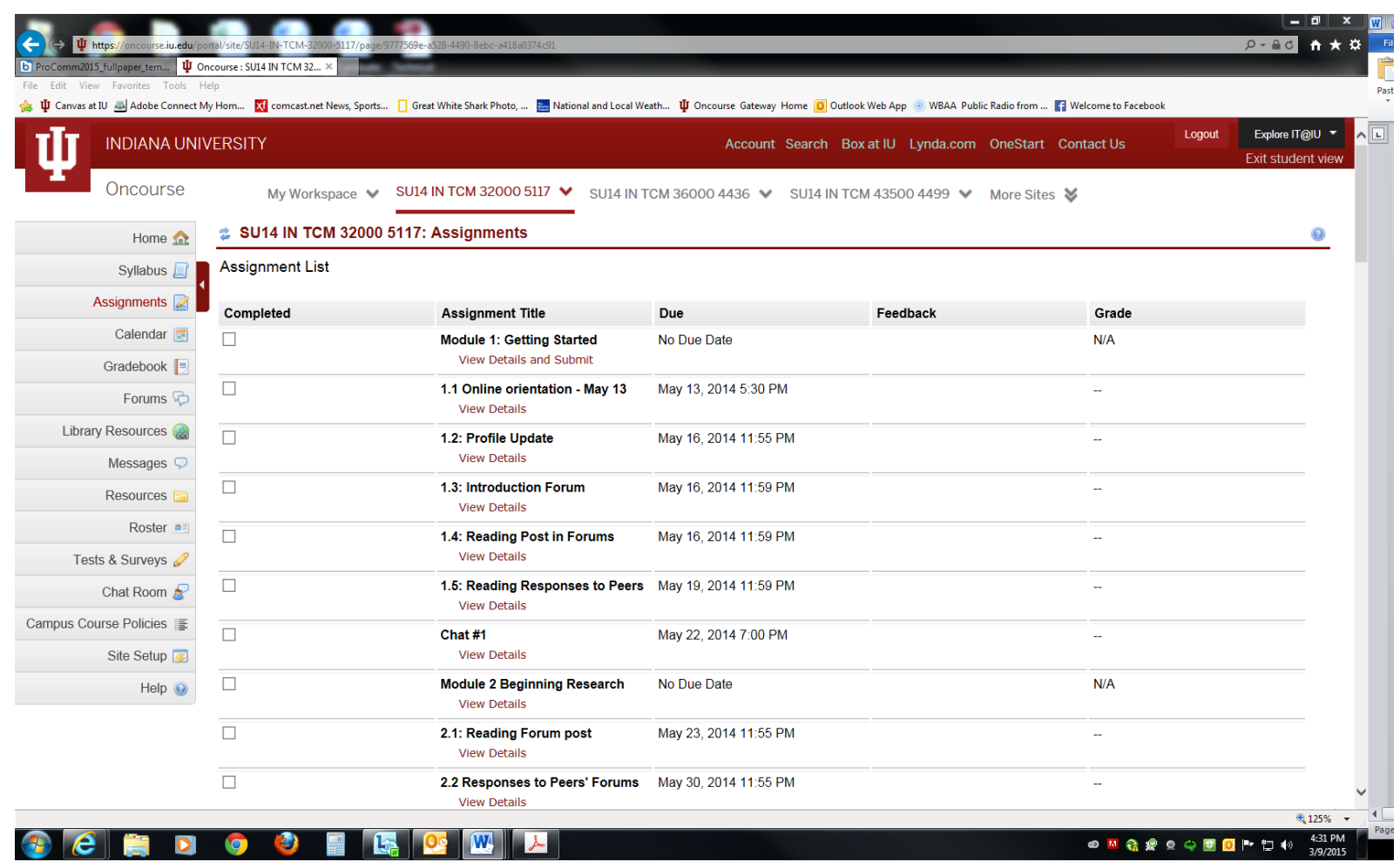

FIGURE 1. SAMPLE INEFFICIENT STUDENT INTERFACE. TO COMPLETE ASSIGNMENT 1.3, STUDENTS NEED TO OPEN THAT ITEM TO READ THE ASSIGNMENT DETAILS AND THEN CLICK ON THE FORUM ITEM IN THE LEFT MENU.

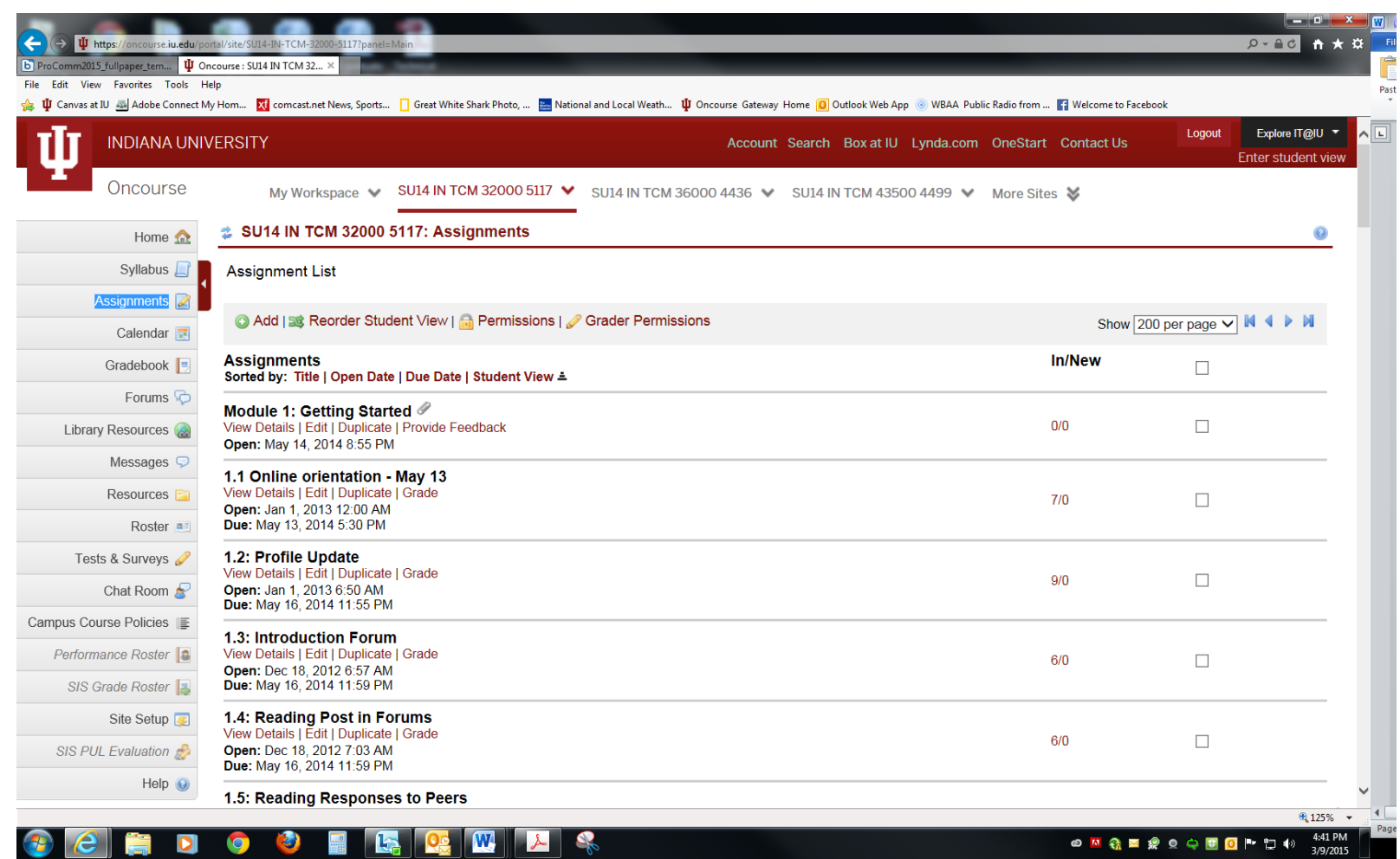

FIGURE 2. SAMPLE EFFICIENT DESIGN FOR DELETING ITEMS IN A LIST. TO DELETE AN ITEM IN ASSIGNMENTS OR RESOURCES, INSTRUCTORS ONLY CHECK A BOX NEXT TO THE ITEM TO BE DELETED, A MORE EFFICIENT APPROACH THAN IS AVAILABLE IN THE GRADEBOOK WHICH REQUIRES MULTIPLE STEPS TO DELETE ONE ITEM. 
As another example of inefficiency, although instructors can migrate materials from an old course into a new one, to update the due dates for assignments, instructors need to open each Assignment item, type in the new due date, and save the item. This process is time consuming, especially when revising many assignments.

Furthermore, Assignments items are linked to the LMS' Gradebook, but when course materials are imported into a new section, those links are broken, so instructors have to go into each Assignment or Gradebook item and restore the links, one by one, also not an efficient use of the instructor's time.

Perhaps the most inefficient feature of this LMS for instructors appears when grading student papers. Students submit the paper electronically in Assignments by uploading it. To grade the submission, the instructor has to download the paper to his/her computer, save it, make comments on the paper, complete a rubric in a separate file, save both files to his/her desktop, insert a grade in the LMS, and upload both files to the LMS for the student to view. This feature is especially problematic for instructors in technical communication and similar courses who have multiple drafts of projects to grade throughout a semester. The process of grading within this LMS takes a great deal of time, beyond giving feedback and determining scores.

\section{Designers may have differing pedagogical assumptions and philosophies which guide the design of the interface}

Even in a usable LMS interface, technical communication pedagogical approaches may require features that interface designers did not initially build into the LMS which may have been created for courses that focus on "attendance and re-presentation of lecture notes rather than interaction, peer review, and authorship" [3, p.1]. Because technical communication courses typically require multiple drafts of student projects, LMS functionality and its concurrent usability go beyond the demands of a content-focused course.

The example in the previous section about problematic means for downloading and uploading students' assignments for grading would not appear in a course that consists solely of lecturing and testing. In a course, such as a technical communication course that is largely project based and therefore requires more interaction for learning, a more efficiently usable interface is desirable.

III. Technical communication faculty members typically do not have time to make a LMS interface more usable or to deal with a inefficient interface

Like many faculty members, technical communication faculty members frequently lack time to make changes to the interface when it is less than optimally usable.

In addition, they may lack time to deal with an interface that uses their time inefficiently, as in the grading example or the Gradebook example mentioned above.

IV. Technical communication faculty members may not have the technical ability to make changes to the interface and/or to design learning experiences that are more usable.

With some exceptions, many technical communication faculty members lack the sophisticated technical abilities to make an interface more usable for students and faculty members. In addition, they lack time to develop the abilities needed to redesign the interface in ways that would make it more usable.

\section{$V$. Usability may take a back seat to other online course design issues and requirements}

Creating an online course is an incredibly complex and time-consuming process. Activities such as preparing materials that help students reach learning objectives, integrating various parts of the LMS, trying to make the learning experience engaging for students, and troubleshooting problems with technology can easily be overwhelming for faculty members.

In such a context, designing an interface to be usable can easily get lost in the complexity of the design process. Even a respected source such as the Quality Matters organization can find itself in such a position [4]. The organization has created a rubric with eight categories for analyzing the quality of various features of online courses. Only in the eighth category (Accessibility and Usability) is the topic of usability mentioned. In that list only two items ask if there is good readability and whether "course multi-media" help with ease of use of a course. However, usability is far more complex than readability and deserves more attention in evaluating the overall quality of online courses.

\section{OPTIONS FOR ADDRESSING THESE CHALLENGES}

Fortunately, people have begun addressing the usability challenges in a LMS interface, as discussed in this section.

In deciding whether to implement these options, faculty members need to consider how the options fit the constraints and resources present in their unique educational contexts.

Not all of these options will apply to every setting, but I present them here in order to provide a range of possibilities for technical communication faculty members who wish to improve the usability of online course.

\section{Conducting heuristic analyses}

Several thinkers advocate using heuristics [1], [5] to assess the quality of an online course. Nielsen's familiar list of usability heuristics could be the basis for such 
analysis, or other lists may work better. (One caveat Nielsen's heuristics were generated with general web sites in mind - the features of an LMS have differing purposes and contexts of use, and so some of the heuristics may need to be modified to accommodate a heuristic analysis of a LMS.)

Heuristics have the advantage of taking less time and energy in assessing usability than more complex usability testing might.

In implementing the use of heuristics, faculty members teaching technical communication and usability could assign their students projects that involve conducting a heuristic analysis of the student-facing portion of the interface and then have students make recommendations to the LMS designers about how to improve the usability of the interface.

\section{Conducting usability testing}

Usability testing [1], [6], [7] of online educational interfaces can determine student and faculty ease of use. Faculty members could conduct this testing if they have access to adequate time and resources, or students could conduct it as a classroom assignment. Even minimal testing can provide useful findings.

Results from the testing could be shared with the designers of the LMS, possibly along with the results of heuristic analyses.

However, if this testing is to be done well, it can take considerable time and energy, so faculty members need to plan carefully and make a case for resources to complete such testing.

\section{Soliciting student and instructor responses}

Approaches that may take less time and energy than usability testing or even heuristic analysis may include analyzing student feedback about the course and/or using the results of web analytics to help course designers understand features of online courses that lead to enhanced usability that supports learning.

If the LMS is designed to provide access to analytics, instructors can employ the results to make arguments to designers about changes to the interface.

Instructors from many courses could also comment on the usability of the LMS, possibly in a focus group. The results of all of these approaches could be shared with designers of the LMS who would be able to make suggested revisions to enhance usability.

\section{$I V$. Providing adequate orientation for students}

Even if one has an optimally usable interface, students - especially those new to online learning - need orientation at the beginning of the course, teaching them how to navigate within the LMS.

I recently conversed with a faculty member who thought his students were "stupid" for not understanding how to navigate within his online course, but he had not provided any orientation at the start of the course so that students could understand how the course materials were structured and how they might navigate among the assignments and activities.

It is easy for course designers to assume that an interface and navigation are "intuitive" when they are not. Even if a student has used the LMS in a previous course, the new instructor may be using it in differing ways that require adjustment on the student's part. For example, in a course I teach, I asked students to submit a group assignment in a specific location. However, the students had previously been in a course using that LMS in which submitting the assignment in a shared group space was all that was required, so they overlooked my instructions of where to submit the assignment in my course. In this instance, their assumptions based on previous experiences over-rode my instructions for where to submit their assignment.

\section{$V$. Lobbying LMS designers for more usable interfaces}

Because many faculty members use LMS interfaces designed by someone else, I advocate that faculty members should try to request more usable interfaces from these designers. The results of the afore-mentioned usability testing, heuristic analysis, student feedback, and/or analytics can provide powerful data that can help support arguments for change.

Reaching these designers will not always be easy. The designers of a commercially-produced interface will not always be responsive to faculty requests. However, technical communication faculty members, with their understandings of usability and technical communication, should be at the forefront of advocating for change and/or participating in institutional decisions about adopting a new LMS or revising an existing one.

My institution recently began the process of replacing its old LMS. Fortunately, those responsible for choosing a new LMS asked faculty members to pilot several different systems in their courses. The decision makers then solicited feedback on the most suitable LMSs.

When Instructure's Canvas was chosen to replace Oncourse, I was pleased to note that it has a built-in mechanism for users to provide feedback to the designers about desirable changes. When a suggestion is submitted, other faculty members from many institutions can "vote" on these changes. The hope is that items with many votes will be implemented in future iterations of the LMS.

\section{Becoming more technically proficient in order to design usable interfaces, even within an existing LMS}

Although faculty members have many demands on their time, they gradually may become more technically proficient in order to design features into an existing LMS that will make it more usable. Each LMS may have flexibility built in, and faculty members should use this 
flexibility to create assignments and activities that are as usable as possible.

In creating materials, faculty members can follow principles of good online usability by keeping wording simple and clear and by focusing on the tasks that the students must complete as they move through assignments and make connections to new knowledge and enhanced abilities. Figure 3 provides an example of the main page one of my courses using Canvas. Note that all assignments are available in one place and that all assignments are phrased as action verbs so that students know what task they will be required to complete in each assignment.

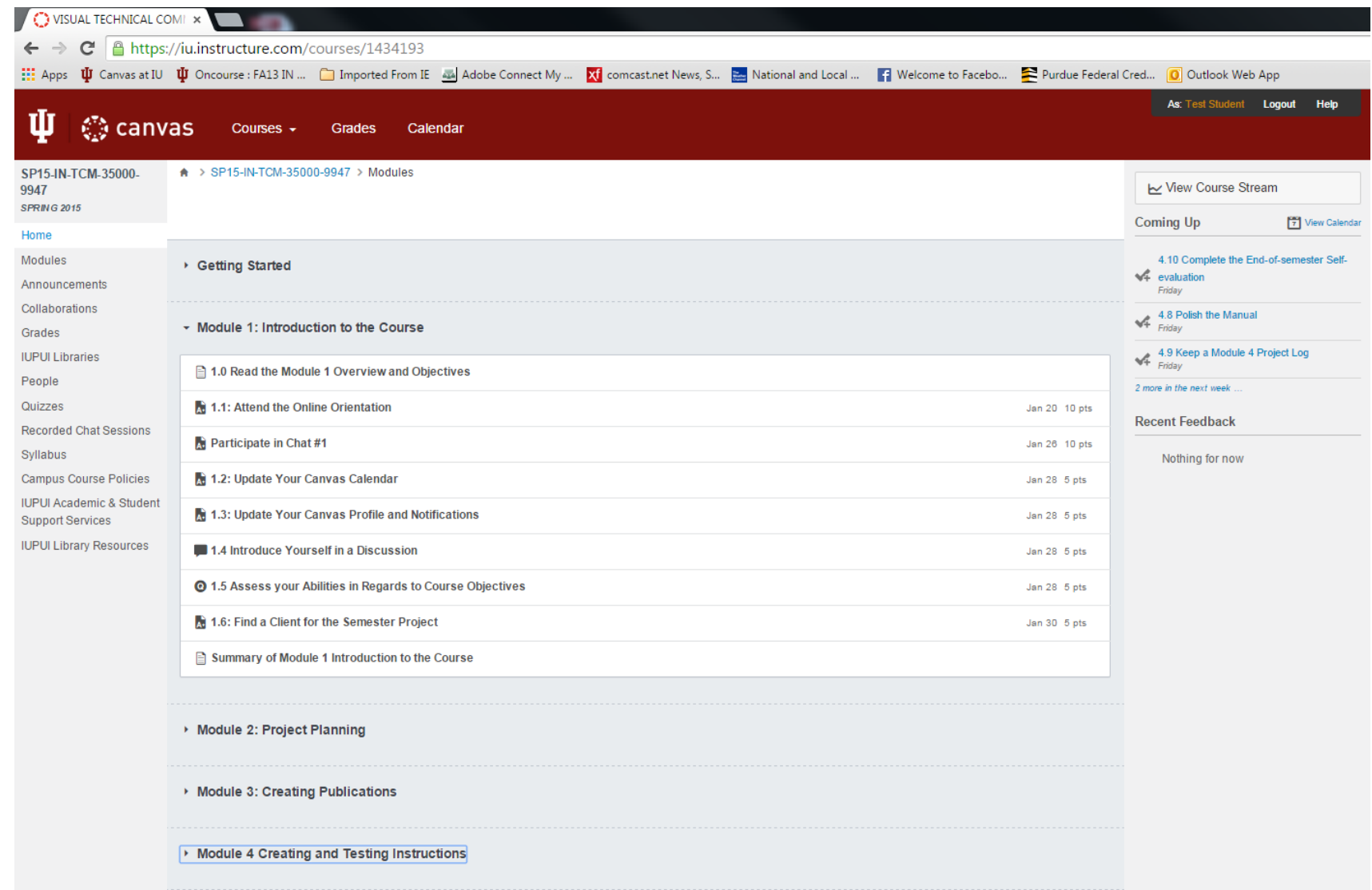

FIGURE 3: EXAMPLE OF WORKING WITHIN EXISTING DESIGN CONDITIONS TO ENHANCE USABILITY. IN THIS SAMPLE SCREEN FROM ONE ONLINE COURSE IN CANVAS, ALL ASSIGNMENTS ARE PHRASED AS ACTIONS AND EASILY AVAILABLE TO STUDENTS IN ONE PLACE.

\section{CONCLUSION}

Designing a usable online course entails addressing multiple challenges, but with careful thought and gradual steps, faculty members can improve the quality of usability in individual courses and can use sound reasoning to encourage the people who make design decisions to move toward online course interfaces that are optimally usable for both students and faculty members.

Options for addressing these challenges as discussed in this article provide a useful starting point for faculty members, especially those in technical communication, who should be at the leading edge of creating usable LMS interfaces for the benefit of students and faculty members who wish benefit from effective, engaging, and educational online courses.

\section{ACKNOWLEDGEMENTS}

The author wishes to thank the IUPUI Center for Teaching and Learning for a Curriculum Enhancement Grant that provided partial support for explorations into developing usable online courses.

\section{REFERENCES}

[1] J. K. Ballard, "Web site usability: A case study of student perceptions of educational web sites," Ph.D. dissertation, University of Minnesota, Minneapolis, MN, 2010. DAI\# 3408366 . 
[2] J. Staggers, et al., "Learning within limits: New faculty and course management software." In Content Management: Bridging the Gap between Theory and Practice, George Pullman and Baotong Gu, Eds. Amityville, N.Y: Baywood, 2008, pp. 57-90.

[3] G. Pullman, and B. Gu, "Introduction," Designing Webbased Applications for $21^{\text {st }}$ Century Writing Classrooms. Amityville, N.Y. Baywood, 2013, pp. 1-6.

[4] Quality Matters Rubric, $5^{\text {th }}$ edition. (2014). [Online] Available: https://www.qualitymatters.org/

[5] J. Nielsen. (1995, January 1). 10 Usability Heuristics for User Interface Design [Online] Available: http://www.nngroup.com/articles/ten-usability-heuristics/
[6] S. A. Bernhardt, "Developing a Web-served handbook for writers," in Designing Web-based Applications for $21^{\text {st }}$ century Writing Classrooms, George Pullman and Bautong Gu, Eds. Amityville, NY: Baywood, 2013, pp. 155-174.

[7] G. McArdle, et al., "Interactive interfaces for presenting online courses: An evaluation study," Paper 159. European Conference on Information Systems (ECIS) 2008 Proceedings. 2008. [Online]. Available: http://aisel.aisnet.org/ecis2008/159

\section{ABOUT THE AUTHOR}

Marjorie Rush Hovde is an Associate Professor of Technical Communication who is interested in usability and excellence in online courses. 